\title{
Discussing sexual health in spinal care
}

\author{
N. S. Korse ${ }^{1}$ M. P. J. Nicolai ${ }^{2}$ S. Both ${ }^{3}$ C. L. A. Vleggeert-Lankamp ${ }^{1}$. \\ H. W. Elzevier ${ }^{2}$
}

Received: 24 January 2015/Revised: 1 May 2015/Accepted: 2 May 2015/Published online: 12 May 2015

(C) The Author(s) 2015. This article is published with open access at Springerlink.com

\begin{abstract}
Background The possible detrimental effects of spinal disease on sexual health are widely recognized; however, it is not known to what extent neurosurgeons discuss this topic with their patients. The aim of this study is to identify knowledge, attitude and practice patterns of neurosurgeons counseling their patients about sexual health.

Methods All members of the Dutch Association of Neurosurgery (neurosurgeons and residents) were sent a questionnaire addressing their attitudes, knowledge and practice patterns regarding discussing sexual health.

Results Response rate was $62 \%$ with 89 questionnaires suitable for analysis. The majority of participants (83\%) were male; mean age, 42.4 years. The mean experience in neurosurgical practice was 9 years. Respondents assumed that in $34 \%$ of their patients, sexual health was affected due to spinal disease. The majority of respondents $(64 \%)$ stated that responsibility for discussing sexual health lies (partly) with the neurosurgeon; however, $73 \%$ indicated to (almost) never do this. The main reasons for not discussing sexual health were patients' old age (42\%), lack of knowledge $(38 \%)$ and lack of patients' initiative to bring up the subject (36\%). Twenty-six percent indicated lack of time as a reason. There was no evidence for gender or
\end{abstract}

N. S. Korse

n.s.korse@lumc.nl

1 Department of Neurosurgery, Leiden University Medical Center, Postzone J11-R-83, Postbus 9600, 2300 RC Leiden, The Netherlands

2 Department of Urology, Leiden University Medical Center, Leiden, The Netherlands

3 Department of Psychosomatic Gynecology and Sexology, Leiden University Medical Center, Leiden, The Netherlands doctor's age discordance as important barriers. Fifty percent of participants wished to gain more knowledge on discussing sexual health with patients.

Conclusion This study shows that despite high prevalence of sexual dysfunction (SD) in spinal patients, counseling about sexual health is not often done in neurosurgical care. More training on sexual health counseling early in the residency program seems critical. By initiating the discussion, clinicians who deal with spinal patients have the potential to detect sexual dysfunction (SD) and to refer adequately when necessary, thereby improving overall quality of life of their patients.

Keywords Spinal cord injury - Cauda equina syndrome . Sexual dysfunction $\cdot$ Counseling $\cdot$ Patient care

\section{Introduction}

Since World War II, numerous studies were published concerning the impact of spinal cord injury on sexual health [18]. Recently, a study was published about the association between low back pain and sexual dysfunction (SD) [9]. Not only physical constraints, but also emotional distress as well as other psychological factors have the potential to change the perception of sexuality in the spinal cord injured $[10,11]$. Alexander et al. reported an incidence of $74 \%$ of relationship difficulties concerning sexual health after spinal cord injury in men [12]. In the last few years, new studies have emerged on sexual health in spinal cord injured women, eliciting the pathophysiology and complicated features of sexual dysfunction (SD) in women with spinal cord injury, and even more general in neurological disease [13-16]. Despite this emerging body of evidence of the extent of the problem of SD in spinal patients, little is known about the 
exact prevalence at presentation or about the recovery, even in specific patient groups such as cauda equina patients, though new studies are emerging $[17,18]$. Despite the problems, spinal cord injured patients face to conduct their sexual activities, literature has advocated their need for sexual expression since the 1970s. Recommendations include enhanced counseling to improve quality of life after spinal cord injury [19]. However, sexual health counseling seems completely neglected by the clinician [20]. Cole found that of quadriplegics and paraplegics who he offered a counseling program for sexual health, $60 \%$ indicated that (almost) no attention was paid to their sexual condition at first presentation in the hospital, and 80-90\% indicated that the hospital staff never or seldom took the initiative to discuss the topic [21]. In Alexander et al. study, only $22 \%$ of spinal cord injured patients received counseling [12]. Recent research into counseling for sexual health in neurosurgical care is almost none existent. This leads to the anomaly that despite the well-documented impact of spinal cord injury on sexual health, no proper study has been conducted among neurosurgeons to explore their counseling practices. Do neurosurgeons incorporate counseling in their clinical care, and if not, for which reasons? To what extent are neurosurgeons actually aware of the problem of sexual dysfunction in their patient population? To explore knowledge, attitudes and practice patterns of neurosurgeons concerning discussing sexual health, this questionnaire survey was conducted among Dutch neurosurgeons. This study is unique in its kind and therefore gives us new insights into the extent of the problem. Due to experience in the clinic, we expected both attention and concern for sexual health in neurosurgical care to be quite poor.

\section{Materials and methods}

\section{Study design}

In March 2013, all members of the Dutch association of Neurosurgery, which comprises of both neurosurgeons and residents in neurosurgery (total 161) were invited to fill in a questionnaire. The questionnaire was developed by the authors of this article, based on the questionnaire used by Nicolai et al. [22], adapted for this purpose. A pilot study was performed in January 2013 among residents and neurosurgeons of the Neurosurgery department of the Leiden University Medical Center. According to feedback and comments, the questionnaire was further adjusted which lead to a finalized version which was used for this survey (See Appendix). The questionnaire ${ }^{1}$ included 34 questions inquiring about several items:

\footnotetext{
${ }^{1}$ Questionnaire is available upon request.
}

1. Demographic data of respondent;

2. Level of knowledge on sexual dysfunction (SD) and its treatment;

3. Frequency of discussing sexual health with patients;

4. Barriers for discussing sexual health with patients;

5. Responsibility of the neurosurgeon to discuss sexual health;

6. Knowledge about (possibilities for) referring patients with SD.

Various questions were asked repetitively for different groups of patients (male, female, age categories) to facilitate analysis regarding patients' sex and age. Questions were all stated referring to patients with general spine problems, unless specified otherwise. Questionnaires were accompanied by an invitation letter explaining reasons for and content of the study and sent by regular mail. A monetary incentive was used to motivate participants to reply. In case a participant did not reply, reminders were sent one month and two months after initial invitation.

\section{Statistical analyses}

Data were analyzed using SPSS Statistics 21.0 (SPSS Inc., Chicago, IL, USA).

Internal consistency of the survey was analyzed using Cronbach's coefficient $\alpha$. Means of numerical demographic values and answers to questions were analyzed with frequencies. Associations between categorical demographic data and numerical variables without Gaussian distribution were tested with the Mann-Whitney $U$ test; for paired data (either numerical without Gaussian distribution or ordinal), Wilcoxon signed rank test was used. When paired data was nominal, analyses were done using McNemar's test. Associations between ordinal or categorical independent variables and ordinal data were calculated with Mantel-Haenszel linear-by-linear association Chi squared test (comparable to Armitage's trend); Pearson Chi square test was used for categorical data.

Comparison of paired ordinal data was done using Friedman's test, with Wilcoxon signed rank test and Bonferroni adjustment as post hoc test. Where associations between ordinal variables and numerical data did not display Gaussian distribution, Kruskal-Wallis $H$ test was performed, with Mann-Whitney $U$ test and Bonferroni adjustment as post hoc test; for numerical demographics and numerical data without Gaussian distribution, Spearman correlation was used. Two-sided $p$ values $<0.05$ were considered statistically significant. Some questions with open, numerical and ordinal answers were grouped together for analyses. 


\section{Results}

\section{Value of questionnaire}

The scores for items regarding the frequency of neurosurgeons asking their patients about sexual health showed a very high internal consistency $(\alpha=0.93)$.

Internal consistency between the items regarding reasons not to inquire about sexual health was good with Cronbach's $\alpha 0.79$.

\section{Participants}

Of the 161 eligible participants, 99 returned the survey, either after first invitation $(n=55)$ or after first $(n=26)$ or second $(n=18)$ reminder, resulting in a total response rate of $61.5 \%$. Eight participants used the option of returning the questionnaire empty with specification of a reason; indicated reasons were lack of experience $(n=3)$, lack of interest $(n=2)$, lack of time $(n=1)$ and other reasons such as working with a specific group of patients not suitable for this study $(n=1)$ or merely treating patients in emergency settings $(n=1)$. One participant returned the questionnaire empty without specifying a reason; another returned it almost empty with too little information available for analysis. This resulted in a total of 89 questionnaires that were suitable for analysis.

Of the participants, $83.3 \%$ were male. Mean age was 42.4 years (SD 9.6), with $71.6 \%$ of respondents being a neurosurgeon versus $28.4 \%$ being a resident. Mean experience in neurosurgical care was 9 years. Of the respondents, $42.5 \%$ indicated to have spinal surgery as his or her specific field of interest. Characteristics of the respondents are summarized in Table 1. Male respondents were significantly older than female respondents [mean age 43.6 (SD 9.43) versus 36.3 (SD 8.35); $p=0.006$ ].

\section{Discussing sexual health}

Participants answered the question 'In how many percent of your patients with general spine problems do you think sexual function has changed because of spine problems?' with a mean of $34.4 \%$ (SD 29.7). Neurosurgeons working in neurosurgical care for a shorter time evaluated this percentage to be higher $(p=0.026)$; so did younger neurosurgeons $(p=0.025)$ and residents $(p=0.023)$. When asked how often sexual health is discussed with patients, $72.4 \%$ said '(almost) never', $20.7 \%$ 'in less than half of the cases', $3.4 \%$ 'in half of the cases', $2.3 \%$ 'in more than half of the cases' and $1.1 \%$ '(almost) always'. Sexual health is significantly less frequently discussed with female than with male patients ( $80.9 \%$ '(almost) never' versus $68.5 \% ; p=0.003)$. This was not statistically significant associated with doctor's gender $(p=0.86)$.

Whether sexual health is discussed, is highly influenced by patients' age. Patients between 20 and 35 years are most often being asked about sexual health (Table 2); this difference is statistically significant $(p<0.0001)$ except between the groups $20-35$ years and $36-50$ years. No significant associations with gender, age or other demographic data of neurosurgeon were found.

Participants consider discussing sexual function more frequently if specific diseases are present; especially in the case of cauda equina syndrome (CES), in which $86.7 \%$ of neurosurgeons discuss sexual health (Table 3). In the specific case of CES, sexual health is significantly less often discussed if the field of interest of the respondent is spinal surgery (78.4 versus $94.0 \% ; p=0.030$ ) and if the neurosurgeon does not feel responsible to discuss sexual health (75.0 versus $94.7 \% ; p=0.007)$. Asking CES patients about sexual health was associated with significantly more referrals to health care professionals specializing in sexual health $(p=0.023)$.

Reasons spontaneously mentioned by respondents to discuss sexual health were spinal dysraphias such as tethered cord $(n=2)$, a HNP fully obtruding the canal $(n=1)$, chronic lumbago $(n=1)$, vascular diseases $(n=1)$ or 'if the patient brings it up' $(n=1)$. One respondent indicated to not discuss SD but to refer to the rehabilitation specialist. Sexual health is never discussed by $4.5 \%$ of respondents, regardless of disease.

\section{Responsibility of discussing sexual health}

Of respondents, $35.3 \%$ believed that the neurosurgeon is responsible for discussing sexual health; $37.5 \%$ disagrees and $27.3 \%$ do not know. The shorter the time spent in neurosurgical care, the more feelings of responsibility are present, though this association only approached statistical significance $(p=0.051)$. Neurosurgeons who deemed themselves responsible discussed sexual health significantly more often $(p=0.006)$. When given a list of options with more than one option possible, $64 \%$ stated that the neurosurgeon is (partly) responsible for discussing sexual health (Table 4). Almost $63 \%$ indicated that it is the patients responsibility, even though the majority of participants $(81.6 \%)$ also stated that patients '(almost) never' bring up sexual health issues themselves. To the question 'Do you mention risks on sexual health when you inform patients about surgery risks (obtaining informed consent)?', $51.7 \%$ said '(almost) never', $19.5 \%$ 'in less than half of the cases', $3.5 \%$ 'in half of the cases', $3.5 \%$ 'in more than half of 
the cases' and $21.8 \%$ '(almost) always'. During check up visits, $69.3 \%$ do not discuss sexual health; $6.8 \%$ does this always.

To the question 'How important is it to screen patients with general spine problems for SD?', $42.7 \%$ stated to find this 'somewhat important', $21.3 \%$ 'important' and $1.1 \%$ 'very important'. It was seen as 'unimportant' by $18 \%$ and the remaining $16.9 \%$ did not know whether it is important. Neurosurgeons who thought screening is important, discussed sexual health significantly more often than those who found it unimportant $(p=0.005)$.

\section{Knowledge}

The majority of respondents $(52.3 \%)$ stated they have 'very little knowledge'; $10.2 \%$ said to have 'no knowledge at all' about SD and treatment options. One-third of respondents said to have 'some knowledge' and $3.3 \%$ describes his/her knowledge as 'sufficient'. More knowledge was associated with more experience in neurosurgical care ( $p=0.046$ ) and higher age of neurosurgeon, though the latter was just not statistically significant $(p=0.052)$. More knowledge was not associated with higher frequency of discussing sexual health $(p=0.565)$. To the question 'Do you wish to enhance your knowledge about discussing sexual health with your patients?' respondents were much divided as $50.6 \%$ answered 'yes' and $49.4 \%$ 'no'. Neurosurgeons below 36 years of age answered significantly more often affirmative (71.4 versus $41.7 \%$; $p=0.034)$ and so did residents (68.0 versus $42.9 \% ; p=0.033)$.

\section{Barriers to discuss sexual health}

Respondents were asked to what extent they agreed with given reasons to not discuss sexual health. Reasons most agreed with were old age of patient (41.6\%), lack of training/knowledge (37.5\%) and lack of patients' initiative to bring up the subject (36\%). Characteristics of respondents were analyzed and several factors were statistically significantly associated with reasons not to inquire about sexual health (Table 5). Lack of time was the third most important barrier (26.1\%), especially for young and inexperienced doctors.

\section{Referring patients}

In the past year, an estimated $1.5 \%$ of patients (SD 5.9) was referred to another health care professional because of SD; $69.8 \%$ of respondents did not refer any patient in the past year. The majority of respondents $(74.2 \%)$ stated to have referral options within their own center, specified in Table 6. Twenty-three percent did not know if there was a health care professional in their center to refer a patient with SD to; this was not significantly associated with the demographics of the neurosurgeon. A directory of health care professional to whom SD patients can be referred to seemed helpful to $66.3 \%$ of respondents; these respondents were significantly younger $(p=0.026)$, more often resident $(p=0.006)$ and had less experience in neurosurgical care $(p=0.004)$.

\section{Discussion}

Sexual health is not often discussed: $72 \%$ of participants (almost) never counsel patients, even though they believe $34 \%$ of patients experiences changes in sexual function due to spinal disease. Sixty-four percent of neurosurgeons believed they were (partly) responsible for discussing sexual health. When obtaining informed consent, $53 \%$ (almost) never discussed risks of surgery on sexual health.

Referring patients to specialized health care workers is not common: $70 \%$ had never referred a patient for SD and $23 \%$ did not know if there was any availability for referral.

The response rate of this study was above the average response rate for physician surveys (54\%) [23]. Several strategies were adopted to attain this high rate, including monetary incentive and using mail-based instead of webbased questionnaires, which have both proven to be effective strategies [24, 25]. Sending reminders boosted response rate from 35 to $62 \%$.

No response bias regarding demographics of respondents could be identified. However, doctors who are not interested in the topic are naturally more likely to have declined invitations. True rates of discussing sexual health may, therefore, be even lower in the general neurosurgeon population, although of the eight doctors returning this questionnaire empty with specification of a reason, only two stated lack of interest as the reason.

Sexual health was more often discussed with male patients and patients aged between 20 and 35 years. Doctor demographics were not associated and it remains unclear why doctors find it less important to inquire about sexual health in female patients than in their male counterparts. Maybe societal biases or the assumed passive sexual role of women which was coined by Higgins years ago, still do play a part [26]. Regarding the latter reason, some might even recall Turks blunt statement in 1983: "During sexual intercourse, the woman is the more passive partner of the two; is receiving while the man is giving, so it is logical to conclude that the act does not affect women as much as it does men" [27]. The respondents predilection of counseling younger patients above older patients is concordant with surveys among other clinicians, showing that sexual health is often neglected in the elderly [22, 28-30]. This is underlined by the fact that $42 \%$ of participants stated that 
'old age of patient' was a reason for not discussing sexual health. Larsen described that sexual activity is most often reduced in elderly people with spinal cord injury, even in the case of complete neurological restitution [31]. Bearing in mind the minimum of counseling done in this older age group, this is not hard to imagine.

Another major reason for not discussing SD found in this study was 'lack of patients initiative to bring up the subject' $(36 \%)$. It is interesting that $63 \%$ of participants stated that patients are responsible to initiate the subject, while $82 \%$ indicated that patients do not bring up the subject themselves. A survey among patients showed that patients prefer the physician to initiate the discussion [32], whereas a different study conducted in primary care stated that patients prefer to initiate the topic themselves, but do not object to doctors who initiate the topic [33]. It seems that by starting the discussion, the doctor simply cannot go wrong.

Naturally, doctors who feel responsible to counsel, discuss sexual health more often. In the specific case of CES, counseling on sexual health is done more frequently by neurosurgeons who feel more confident about their knowledge of sexual health. For the general group of patients, however, this was not the case: doctors with more knowledge did not counsel more often. Despite this fact, $37 \%$ of participants did indicate 'lack of knowledge' as a barrier to discuss sexual health. This seems reasonable, since merely $3 \%$ of respondents rated their knowledge on SD as sufficient. Lack of knowledge is often described in literature as an important barrier to discussing sexual health, with Bachmann reporting in his survey including physicians and gynecologists, amongst others, that $22 \%$ of respondents rated their knowledge and comfort level of discussing sexual female health as poor [34]. This advocates the incorporation of counseling on sexual health in the curriculum, as was proposed by other authors $[35,36]$. What this study adds to current knowledge, is that the majority of participants is eager to enhance their knowledge, especially young doctors, which offers opportunities to invest in counseling training early in residencies.

The introduction of proper checklists to detect SD could be helpful in this light. Defining female sexual dysfunction can be quite challenging. To cater for this problem, Sipski et al. proposed a classification of female sexual dysfunction after spinal cord injury, dividing dysfunction into four categories, including psychogenic and reflex genital arousal [37]. In 2007, due to increased attention for this topic, the American Spinal Injury Association released a standard form to assess sexual function in spinal cord injured patients of both sexes, with items including genital arousal, orgasm and sensation of menses/ejaculation [38].

Regarding the right time to counsel about sexual health, the critical interval for discussing sexual health with spinal cord injured patients was earlier found to be up to 6 months after inpatient rehabilitation [39]. Bearing this in mind, clinicians can maximize the impact of their counseling. Therapeutic options for SD in spinal cord injured are available and have been evaluated in various studies, though since this is beyond the scope of this article, they will not be discussed here [40-42]. It is sufficient for the counseling doctor to know that there are solutions to this often neglected problem, which makes counseling all the more beneficial.

Lack of time was a barrier for only a reasonably small group of participants $(26.1 \%)$, in contrast to surveys conducted among other clinicians [22, 34, 43, 44]. The same applied for reasons such as embarrassment, age and gender discordance and ethnic differences [29, 30, 34, 43].

\section{Conclusion}

For the last decades, a body of knowledge has arisen laying down the fundamental concepts of possible sexual health changes in spinal patients. This study shows that counseling is not often done in neurosurgical care, mainly due to lack of knowledge/training, old age of patients and lack of patients initiative. To enhance counseling facilities, more training on sexual health counseling early in the residency program seems critical. By initiating the discussion, clinicians who deal with spinal patients have the potential to detect SD and refer adequately when necessary, thereby improving the overall quality of life of their patients.

\section{Conflict of interest None.}

Open Access This article is distributed under the terms of the Creative Commons Attribution 4.0 International License (http:// creativecommons.org/licenses/by/4.0/), which permits unrestricted use, distribution, and reproduction in any medium, provided you give appropriate credit to the original author(s) and the source, provide a link to the Creative Commons license, and indicate if changes were made.

\section{Appendix}

See Tables 1, 2, 3, 4, 5 and 6. 
Table 1 Characteristics of participants $(n=89)$

\begin{tabular}{lc}
\hline & $n(\%)$ \\
\hline Sex & $74(83.3)$ \\
Male & $15(16.7)$ \\
Female & $42.4($ SD 9.6$)$ \\
Mean age (years) & \\
Function & $63(71.6)$ \\
Neurosurgeon & $25(28.4)$ \\
Resident & \\
Place of practice & $40(45.5)$ \\
University hospital & $15(17.0)$ \\
Teaching hospital & $3(3.4)$ \\
District general hospital & $23(26.1)$ \\
University + district general hospital & $6(6.8)$ \\
University + teaching hospital & $1(1.1)$ \\
University + district general + teaching & \\
Experience in neurosurgical practice (years) & $3(3.4)$ \\
$<3$ & $11(12.4)$ \\
$3-5$ & $25(28.1)$ \\
$6-10$ & $15(16.9)$ \\
$11-15$ & $35(39.3)$ \\
$>15$ & $37(42.5)$ \\
Has spinal surgery as field of interest &
\end{tabular}

$n$ differs because some questions were skipped

Table 2 When do you discuss sexual health: influence of patients' age

\begin{tabular}{lllcl}
\hline $\begin{array}{l}\text { Patients age } \\
\text { (years) }\end{array}$ & $\begin{array}{l}\text { Never } \\
(\%)\end{array}$ & $\begin{array}{l}\text { Seldom } \\
(\%)\end{array}$ & $\begin{array}{l}\text { Regularly } \\
(\%)\end{array}$ & $\begin{array}{l}\text { Often } \\
(\%)\end{array}$ \\
\hline$<20$ & 44.8 & 44.8 & 8.0 & 2.3 \\
$20-35$ & 36.8 & 47.1 & 13.8 & 2.3 \\
$36-50$ & 36.8 & 49.4 & 11.5 & 2.3 \\
$51-65$ & 55.2 & 35.6 & 6.9 & 2.3 \\
$66-75$ & 69 & 28.7 & 2.3 & 0 \\
$>75$ & 73.5 & 25.3 & 1.1 & 0 \\
\hline
\end{tabular}

Table 3 Do you discuss sexual health for these specific diseases?

\begin{tabular}{ll}
\hline Pathology & Yes $(\%)$ \\
\hline Cauda equina syndrome & 87.6 \\
Paraplegia & 82.0 \\
Tumor of myelum or spine & 70.8 \\
Spinal fracture & 36.4 \\
Hernia nuclei pulposi & 23.6 \\
Degenerative disease other than HNP & 11.2 \\
Never & 4.5
\end{tabular}

Total adds up to $>100 \%$ since more than one answer was possible

Table 4 Who is responsible for discussing SD?

\begin{tabular}{lc}
\hline & $\%$ \\
\hline Neurosurgeon & 64.0 \\
Patient & 62.9 \\
General practitioner & 57.3 \\
Neurologist & 57.3 \\
Partner of patient & 25.8 \\
Sexologist & 15.7 \\
Nurse & 7.9 \\
Psychologist & 7.9 \\
Social worker & 6.7 \\
Other: rehabilitation specialist & 6.7 \\
Physiotherapist & 4.5 \\
Other: urologist & 2.2 \\
Other: gynecologist & 1.1 \\
Other: spine center team & 1.1 \\
Other: doctors in general & 1.1 \\
Other: depends on context/disease & 6.7 \\
\hline
\end{tabular}

Total adds up to $>100 \%$ since more than one answer was possible 
Table 5 Barriers for inquiring about sexual health

\begin{tabular}{|c|c|c|c|c|c|c|}
\hline Barriers & $\begin{array}{l}\text { Strongly agree } \\
(\%)\end{array}$ & $\begin{array}{l}\text { Agree } \\
(\%)\end{array}$ & $\begin{array}{l}\text { Neutral } \\
(\%)\end{array}$ & $\begin{array}{l}\text { Disagree } \\
(\%)\end{array}$ & $\begin{array}{l}\text { Strongly } \\
\text { disagree }(\%)\end{array}$ & $\begin{array}{l}\text { Doctors' characteristics associated } \\
\text { with agreeing ( } p \text { value) }\end{array}$ \\
\hline Old age of patient & 5.6 & 36.0 & 28.1 & 18.0 & 12.4 & None \\
\hline $\begin{array}{l}\text { Lack of } \\
\text { training/knowledge }\end{array}$ & 6.8 & 30.7 & 30.7 & 18.2 & 13.6 & Less experience $(0.028)$ \\
\hline Lack of patients initiative & 3.4 & 32.6 & 19.1 & 28.1 & 16.9 & Less responsibility (0.002) \\
\hline Lack of time & 6.8 & 19.3 & 23.9 & 31.8 & 18.2 & $\begin{array}{l}\text { Young age }(0.037) \text {; less experience } \\
(0.020)\end{array}$ \\
\hline $\begin{array}{l}\text { Language/ethnicity/ } \\
\text { religion }\end{array}$ & 2.2 & 20.2 & 33.7 & 27.0 & 16.9 & None \\
\hline $\begin{array}{l}\text { Someone else's } \\
\text { responsibility }\end{array}$ & 3.4 & 14.6 & 31.5 & 36.0 & 14.6 & Less responsibility $(<0.0001)$ \\
\hline Patient is too ill & 0 & 12.4 & 24.7 & 39.3 & 23.6 & None \\
\hline Patient is not ready for it & 0 & 3.4 & 23.6 & 46.1 & 27.0 & None \\
\hline $\begin{array}{l}\text { Shame to bring up the } \\
\text { subject }\end{array}$ & 0 & 3.4 & 22.5 & 44.9 & 29.2 & More responsibility $(0.018)$ \\
\hline Age discordance & 0 & 1.1 & 12.4 & 50.6 & 36.0 & None \\
\hline $\begin{array}{l}\text { Patient is of the opposite } \\
\text { sex }\end{array}$ & 1.1 & 0 & 7.9 & 47.2 & 43.8 & None \\
\hline
\end{tabular}

Table 6 Where to do you refer patients for SD? $(n=21)$

\begin{tabular}{lr}
\hline Urologist & 10 \\
Sexologist & 10 \\
Gynecologist & 5 \\
Rehabilitation specialist & 2 \\
Fertility clinic & 2 \\
Spine center team & 1 \\
Plastic surgeon for co-aptation of pudendal nerve & 1
\end{tabular}

Total adds up to $>21$ since some gave more answers

\section{References}

1. Munro D, Horne HW Jr, Paull DP (1948) The effect of injury to the spinal cord and cauda equina on the sexual potency of men. N Engl J Med 239(24):903-911

2. Talbot HS (1949) A report on sexual function in paraplegics. J Urol 61(2):265-270

3. Talbot HS (1955) The sexual function in paraplegia. J Urol 73(1):91-100

4. Zeitlin AB, Cottrell TL, Lloyd FA (1957) Sexology of the paraplegic male. Fertil Steril 8(4):337-344

5. Weiss AJ, Diamond MD (1966) Sexual adjustment, identification, and attitudes of patients with myelopathy. Arch Phys Med Rehabil 47(4):245-250

6. Jochheim KA, Wahle H (1970) A study on sexual function in 56 male patients with complete irreversible lesions of the spinal cord and cauda equina. Paraplegia 8(3):166-172

7. Comarr AE (1970) Sexual function among patients with spinal cord injury. Urol Int 25(2):134-168

8. Benevento BT, Sipski ML (2002) Neurogenic bladder, neurogenic bowel, and sexual dysfunction in people with spinal cord injury. Phys Ther 82(6):601-612
9. Nikoobakht $\mathrm{M}$ et al (2014) Sexual function and associated factors in Iranian patients with chronic low back pain. Spinal Cord 52(4):307-312

10. Teal JC, Athelstan GT (1975) Sexuality and spinal cord injury: some psychosocial considerations. Arch Phys Med Rehabil 56(6):264-268

11. Kreuter M, Sullivan M, Siosteen A (1996) Sexual adjustment and quality of relationship in spinal paraplegia: a controlled study. Arch Phys Med Rehabil 77(6):541-548

12. Alexander CJ, Sipski ML, Findley TW (1993) Sexual activities, desire, and satisfaction in males pre- and post-spinal cord injury. Arch Sex Behav 22(3):217-228

13. Sipski ML, Alexander CJ, Rosen RC (1995) Orgasm in women with spinal cord injuries: a laboratory-based assessment. Arch Phys Med Rehabil 76(12):1097-1102

14. Sipski ML, Alexander CJ, Rosen RC (1999) Sexual response in women with spinal cord injuries: implications for our understanding of the able bodied. J Sex Marital Ther 25(1):11-22

15. Sipski ML, Alexander CJ, Rosen R (2001) Sexual arousal and orgasm in women: effects of spinal cord injury. Ann Neurol 49(1):35-44

16. Sipski ML (2001) Sexual function in women with neurologic disorders. Phys Med Rehabil Clin N Am 12(1):79-90

17. Korse NS et al (2013) Complaints of micturition, defecation and sexual function in cauda equina syndrome due to lumbar disk herniation: a systematic review. Eur Spine J 22(5):1019-1029

18. Tamburrelli FC et al (2014) Cauda equina syndrome: evaluation of the clinical outcome. Eur Rev Med Pharmacol Sci 18(7):1098-1105

19. Siosteen A et al (1990) Sexual ability, activity, attitudes and satisfaction as part of adjustment in spinal cord-injured subjects. Paraplegia 28(5):285-295

20. Jackson RW (1972) Sexual rehabilitation after cord injury. Paraplegia 10(1):50-55

21. Cole TM, Chilgren R, Rosenberg P (1973) A new programme of sex education and counselling for spinal cord injured adults and health care professionals. Paraplegia 11(2):111-124

22. Nicolai MP et al (2013) Discussing sexual function in the cardiology practice. Clin Res Cardiol 102(5):329-336 
23. Asch DA, Jedrziewski MK, Christakis NA (1997) Response rates to mail surveys published in medical journals. J Clin Epidemiol 50(10):1129-1136

24. Leece $P$ et al (2004) Internet versus mailed questionnaires: a randomized comparison (2). J Med Internet Res 6(3):e30

25. VanGeest JB, Johnson TP, Welch VL (2007) Methodologies for improving response rates in surveys of physicians: a systematic review. Eval Health Prof 30(4):303-321

26. Higgins GE Jr (1979) Sexual response in spinal cord injured adults: a review of the literature. Arch Sex Behav 8(2):173-196

27. Turk R, Turk M, Assejev V (1983) The female paraplegic and mother-child relations. Paraplegia 21(3):186-191

28. Gott M, Hinchliff S, Galena E (2004) General practitioner attitudes to discussing sexual health issues with older people. Soc Sci Med 58(11):2093-2103

29. Gott M et al (2004) "Opening a can of worms": GP and practice nurse barriers to talking about sexual health in primary care. Fam Pract 21(5):528-536

30. Burd ID, Nevadunsky N, Bachmann G (2006) Impact of physician gender on sexual history taking in a multispecialty practice. J Sex Med 3(2):194-200

31. Larsen E, Hejgaard N (1984) Sexual dysfunction after spinal cord or cauda equina lesions. Paraplegia 22(2):66-74

32. Metz ME, Seifert MH Jr (1990) Men's expectations of physicians in sexual health concerns. J Sex Marital Ther 16(2):79-88

33. Clark RD, Williams AA (2014) Patient preferences in discussing sexual dysfunctions in primary care. Fam Med 46(2):124-128

34. Bachmann G (2006) Female sexuality and sexual dysfunction: are we stuck on the learning curve? J Sex Med 3(4):639-645

35. Vollmer S et al (1989) Improving the preparation of preclinical students for taking sexual histories. Acad Med 64(8):474-479
36. Rosen $\mathrm{R}$ et al (2006) Sexual communication skills in residency training: the Robert Wood Johnson model. J Sex Med 3(1):37-46

37. Sipski ML, Alexander CJ (2002) Documentation of the impact of spinal cord injury on female sexual function: the female spinal sexual function classification. Top Spinal Cord Inj Rehabil 8(1):63-73

38. Sipski Alexander M, Biering-Sorensen F, Charlifue S, Dietz V et al (2014) The international standards to document remaining autonomic function after spinal cord injury. http://www.asia-spi nalinjury.org/elearning/ASIA_Auto_Stan_Worksheet_2012.pdf. Accessed 8 Dec 2014

39. Fisher TL et al (2002) Sexual health after spinal cord injury: a longitudinal study. Arch Phys Med Rehabil 83(8):1043-1051

40. Sipski ML et al (2000) Sildenafil effects on sexual and cardiovascular responses in women with spinal cord injury. Urology 55(6):812-815

41. Derry F et al (2002) Efficacy and safety of sildenafil citrate (Viagra) in men with erectile dysfunction and spinal cord injury: a review. Urology 60(2 Suppl 2):49-57

42. Rahimi-Movaghar V, Vaccaro AR (2012) Management of sexual disorders in spinal cord injured patients. Acta Med Iran 50(5):295-299

43. Abdolrasulnia M et al (2010) Management of female sexual problems: perceived barriers, practice patterns, and confidence among primary care physicians and gynecologists. J Sex Med 7(7):2499-2508

44. Alarcao V et al (2012) General practitioners' knowledge, attitudes, beliefs, and practices in the management of sexual dysfunction-results of the Portuguese SEXOS study. J Sex Med 9(10):2508-2515 